\section{EDUCAÇÃO EM SAÚDE COM MULHERES ACERCÁ DO CLIMATÉRIO - RELATO DE UMA AÇÃO EXTENSIONISTA}

\section{HEALTH EDUCATION WITH WOMEN ABOUT THE CLIMATE - REPORT OF AN EXTENSIONIST ACTION}

Daiane dos Santos Souza ${ }^{1} /$ Darlyane Antunes Macedo ${ }^{1, *}$

\section{INTRODUÇÃO}

O climatério é definido pela Organização Mundial de Saúde - OMS, como o período de transição da fase reprodutiva para a fase não reprodutiva, fazendo parte de um processo fisiológico na vida das mulheres. Subsequente ao esgotamento folicular ovariano, e que sobrevém a todas as mulheres, começando geralmente de 30 a 40 anos e encerrando-se aos 65 (BRASIL, 2008).

A fase do climatério tem como marco principal a menopausa que condiz ao último ciclo menstrual, sendo identificado de forma retroativa, após 12 meses de amenorreia, sobrevindo em média aos 50 anos de idade, constituindo um episódio inevitável por se tratar de uma fase biológica como dito anteriormente. No entanto, apesar de não ser um momento patológico na vida da mulher é um período de grandes dúvidas, mudanças e anseios (BRASIL, 2008).

A maioria das mulheres refere-se a algum tipo de sintomatologia durante o climatério, as manifestações clínicas que são características desse período, tais como fogachos, alterações de humor, dores de cabeça, suor frio, atrofia urogenital, sendo justificadas pelo estado de diminuição dos níveis de estrogênio, chamado de hipoestrogenismo, e que corresponde à queda ou decrescimento significativo de estrogênio (BRASIL, 2008).

É notável o número de mulheres que se encontra no período do climatério e, no entanto não reconhecem que grande parte das alterações hormonais, físicas ou emocionas que ocorrem sejam características dessa fase, podendo assim agravar seu estado de insegurança e instabilidade. A assistência educativa se faz extremamente necessária, uma vez que se inicia uma nova fase do ciclo de vida feminino (DIÓGENES; LINARD; TEIXEIRA, 2010; DE LYRA SOUSA, 2012).

\begin{abstract}
RESUMO
METODOLOGIA: Trata-se de um relato de experiência sobre intervenção extensionista, construída por acadêmicas do curso de Bacharelado em Enfermagem, membros do projeto de extensão "Mulheres no Climatério - Educação e Saúde em Unidade de Saúde da Família" da Universidade do Estado da Bahia, Campus XII. OBEJETIVO: descrever ação extensionista, com mulheres na fase do climatério. RESULTADOS: Foram elucidadas, de modo não estruturado - descontraído, as respostas para algumas perguntas acerca da temática climatério e menopausa. Esclarecendo que grande maioria das mulheres refere algum tipo de sintomatologia durante o climatério, e que o reconhecimento antecipado dos agravos acometidos durante essa fase, pode auxiliar na qualidade de vida. CONCLUSÃO: Conclui-se que momentos como o promovido pelo projeto é relevante para a promoção da qualidade de vida.
\end{abstract}

Palavras-chave: Climatério. Qualidade de vida. Saúde da mulher.

\section{ABSTRACT}

METHODOLOGY: This is an experience report on extension intervention, built by undergraduate Nursing students, members of the extension project "Women in Climacteric Education and Health in the Family Health Unit" at the State University of Bahia, Campus XII. OBJECTIVE: describe an extension action, with women in the climacteric phase. RESULTS: The answers to some questions about the climacteric and menopause were elucidated in an unstructured - relaxed way. Clarifying that the vast majority of women report some type of symptoms during the climacteric, and that the early recognition of the diseases affected during this phase, can help in the quality of life. CONCLUSION: It is concluded that moments like the one promoted by the project are relevant to the promotion of quality of life.

Keywords: Climacteric. Quality of life. Women.

Submetido em: 08 de nov. 2019

Aceito em: 14 de fev. 2020

${ }^{1}$ Universidade do Estado da Bahia - UNEB, Guanambi, Bahia - Brasil.

*E-mail para correspondência: damacedo@uneb.br

Rev. ComCiência - jun. 2020, vol. 5, no. 6, p. 100-103 / doi: 10.36112/ issn2595-1890.v5.i6.p100-103 
$\mathrm{Na}$ enfermagem utilizar a educação como forma de cuidar, intensifica a assistência, construindo relações de troca de saberes e experiências, ultrapassando uma simples forma de cuidar, configurando uma estratégia de cuidado. Além de utilizar a educação em saúde como ferramenta para o cuidar, o planejamento voltado para um acolhimento pode agir de forma resolutiva frente as queixas presentes no período do climatério (DE LYRA SOUSA, 2012).

A educação em saúde soma ao climatério possibilitando a junção entre profissional de enfermagem e mulher, criando um ambiente de reflexão com fundamentação cientifica e popular, estimulando mudanças de cunho particular e coletivo uma vez que o(a) profissional pode elucidar todas as mudanças fisiológicas que ocorrem durante a fase, a fim de preparar a mulher para o marco principal do climatério que é a menopausa, minimizando os consequentes impactos, gerando bem estar e qualidade de vida (DIÓGENES; LINARD; TEIXEIRA, 2010).

As ações educativas são ferramentas do profissional de saúde, seja no mundo do trabalho ou quando ainda esta em processo de formação na academia. Nesse sentido, a universidade pode lançar mão desse recurso de diversos modos, seja nas ações práticas de ensino, em pesquisas desenvolvidas, mas sobretudo nas ações extensionistas, pois essas são estruturadas para a comunidade, pensando em construção coletiva, onde a universidade é uma mediadora no processo de construção e a comunidade é protagonista do seu próprio conhecimento.

A ação extensionista universitária tem papel relevante nas contribuições que a universidade pode dar a sociedade, pois promove a oportunida- de de fundamentação cientifica e popular, colocando em prática na comunidade o que foi aprendido em sala de aula. Além de trocar com a comunidade o que se aprende dentro dos muros acadêmicos, a extensão universitária faz com que o acadêmico aprenda muito mais que a teoria é capaz de ensinar, uma vez que ter o contato com a comunidade traz para o espaço da universidade aquilo que a sociedade tem a oferecer com o seu conhecimento popular e cultural, sendo beneficiada ambas as partes, e tornando a teoria muito mais prazerosa (RODRIGUES et al, 2013).

Desse modo, esse trabalho pretende descrever ações de extensão, com mulheres na fase do climatério, onde a ferramenta escolhida para intervenção é a educação em saúde o que se torna relevante, pois poderá contribuir com a estruturação de ações de profissionais de saúde, assim como de acadêmicos ainda na universidade.

\section{MATERIAIS E MÉTODOS}

Trata-se de um relato de experiência sobre ação extensionista, construída por acadêmicas do curso Bacharelado em Enfermagem, membros do projeto de extensão "Mulheres no Climatério - Educação e Saúde em Unidade de Saúde da Família" da Universidade do Estado da Bahia, Campus XII.

Inicialmente as atividades foram realizadas na universidade - UNEB, planejadas previamente por meio de um calendário de intervenções, articulado com a participação da coordenadora do projeto de extensão juntamente com as demais monitoras e unidades que receberam ações do projeto.

Posteriormente foi desenvolvida uma intervenção com mulheres de idades diversas, essa foi iniciada por meio de dinâmica de apresentação com uma caixa de fósforo, orientando que cada uma delas ao pegar a caixa, retirasse um palito de fósforo para acender a chama do palito e enquanto essa chama durasse elas poderiam se apresentar dizendo nome, idade, se tem filhos ou não, e demais informações que achassem pertinentes.

Logo após a apresentação, foi realizada uma atividade com a participação e interação de todas as mulheres, varal de perguntas e resposta, expondo algumas frases: Já ouviu falar em Climatério? O que é menopausa? Sabe descrever alguns sinais e sintomas frequentes nessa fase? Quanto tempo dura o climatério? Com quantos anos a menstruação começa a falhar?

A metodologia escolhida visa promover um momento menos estruturado, menos formal, capaz de extrair o máximo de informações acerca das percepções e sentimentos das participantes e assim favorecer a troca de conhecimento acerca da temática.

Por se tratar de um relato de experiência não foi necessário a submissão ao Comitê de Ética em Pesquisa, contudo foram tomados todos os cuidados inerentes a um trabalho com seres humanos, no que tange a resolução n. ${ }^{\circ} 466$ de 12 de dezembro de 2012, sobretudo mantendo o sigilo acerca das participantes.

\section{RESULTADOS E DISCUSSÃO}

A atividade foi estruturada de modo que não gerasse a ideia de palestra, pois pretendeu-se promover um momento de troca e construção de conhecimento, onde o que foi proposto fosse relevante para quem participa. Para tanto, iniciou-se com uma dinâmica de apresentação, seguida da intervenção - varal de perguntas e res- 
postas, promoção de espaço de relaxamento e avaliação da intervenção.

O método escolhido para apresentação das participantes, já promoveu um momento de descontração entre as mulheres e nós membros do projeto, pois muitas que estavam acanhadas, com o auxílio das demais ficou cada vez mais à vontade, e assim trouxe leveza a intervenção.

A participação das mulheres nesse momento foi de quase totalidade das participantes, com exceção de duas que preferiram não participar. No entanto, esse momento já foi capaz de sensibilizá-las acerca da atividade proposta, pois durante a atividade extensionista perguntaram e contribuíram com suas experiências. As demais, durante a dinâmica se apresentaram e de modo geral traziam curiosidades sobre aquele momento e especialmente porque apenas mulheres estavam ali presentes.

Durante a intervenção propriamente dita, foram elucidadas, de forma descontraída, as respostas para algumas perguntas acerca da temática climatério e menopausa. As perguntas foram apresentadas gradativamente, e permitindo a interação entre as monitoras e participantes da intervenção. Esse processo de jogar as perguntas para o coletivo, promoveu muitas inquietudes, mas sobretudo troca, pois a idade variada, com histórias de vida diversas contribuiu muito para esse momento.

Com a intervenção, foi possível esclarecemos que a grande maioria das mulheres refere algum tipo de sinal e/ou sintoma durante o climatério, e que o reconhecimento antecipado dos agravos acometidos durante essa fase, pode auxiliar na promoção da qualidade de vida.

As dúvidas mais frequentes, fo- menopausa, acerca das mudanças e como e quando irão passar, assim como sobre a sexualidade nessa fase. Essas questões foram discutidas no coletivo que participava da intervenção e servirão como norteadoras para estruturação de novas intervenções com esse grupo de mulheres.

Ao término da explanação sobre a temática, acadêmicas do curso de educação física, também monitoras do projeto, promoveram um momento de atividades laborais, enfatizando exercícios físicos dos quais elas poderiam desenvolver de maneira independente em casa.

Ao final da intervenção realizamos uma avaliação da intervenção pelas mulheres, sendo entregues placas que caracterizava a intervenção como ruim, boa e ótima. A atividade proposta e realizada foi recebida de forma positiva e avaliada como ótima, por discutir uma temática de interesse e pouco abordada.

O climatério é um período de incertezas devido a diversas mudanças físicas e psicológicas na vida da mulher, além destas estão presentes influências de diversos fatores como familiares, culturais, ambientais; atingindo e repercutindo cada mulher de uma forma particular e significativa (BELTRAMINI, 2010).

Em vista disso, para que as mulheres possam vivenciar o período do climatério com qualidade é de suma importância que haja uma assistência voltada para esse ciclo, por meio da educação em saúde estimulando a curiosidade sobre essa fase e principalmente o autocuidado com a saúde, com intuito de diminuir as repercussões e abalos gerados no processo de mudanças físicas e psicológicas que comumente acontece durante o climatério (BELTRAMINI, 2010).

\section{CONCLUSÃO}

Diante do exposto conclui-se que momentos como o promovido pelo projeto de extensão é relevante para a promoção da qualidade de vida de mulheres; contribui para o crescimento de acadêmicos que se envolvem com a extensão, o que tem potencial para gerar um egresso profissional diferenciado e sensível as questões de saúde da mulher quando forem para o mundo do trabalho.

Nesse sentido, compreende-se que a extensão universitária tem um papel primordial, pois é uma das partes da universidade capaz de agregar o conhecimento científico com o popular, provocando mudanças nos dois coletivos - comunidade e universidade.

Destaca-se também que estudos para avaliar profundamente o impacto dessas ações são necessários para fortalecer ações de Educação em Saúde em diversos campos, assim como a construção de intervenções extensionistas em áreas diversificadas do conhecimento, pois poderão contribuir como esse trabalho, para mudança de paradigmas de assistência, assim como na formação discente de um egresso profissional mais sensível a realidade da comunidade.

\section{REFERÊNCIAS}

BRASIL. Ministério Da Saúde. Manual de atenção à mulher no climatério/menopausa. Ministério da Saúde, 2008.

BELTRAMINI, Amanda Carla dos Santos et al. Atuação do enfermeiro diante da importância da assistência à saúde da mulher no climatério. Revista mineira de enfermagem, v. 14, n. 2, p. 166-174, 2010. ram sobre o conceito de climatério e 
DIÓGENES, Maria Albertina Rocha; LINARD, Andrea Gomes; TEIXEIRA, Carla Araujo Bastos. Comunicação, acolhimento e educação em saúde na consulta de enfermagem em ginecologia. Revista da Rede de Enfermagem do Nordeste, v. 11, n. 4, p. 38-46, 2010.

RODRIGUES, Andréia Lilian Lima et al. Contribuições da extensão universitária na sociedade. Caderno de Graduação-Ciências Humanas e SociaisUNIT, v. 1, n. 2, p. 141-148, 2013.

DE LYRA SOUSA, Jéssica et al. Educação em saúde como ferramenta à mulher no climatério: subsídios para o cuidado de enfermagem. Revista de Pesquisa Cuidado é Fundamental Online, v. 4, n. 1, p. 2616-2622, 2012. 